\title{
Influence of the nature of the alkanethiol terminal group on the electrochemical stability and blocking ability of self-assembled nanofilms on Au electrode
}

\author{
Svetlana. Ovchinnikova ${ }^{1-}$, Tatyana Aleksandrova ${ }^{1,2}$ \\ ${ }^{1}$ Institute of Solid State Chemistry and Mechanochemistry of the Siberian Branch of the Russian \\ Academy of Sciences, Êutateladze Street, 18, Novosibirsk, Novosibirsk, 630128, Russia,
}

${ }^{2}$ Novosibirsk State Technical University, 20, Karl Marx prospekt, Novosibirsk, 630073, Russia

\begin{abstract}
We studied the effect of the nature of the terminal group of thiols with the same chain length $\mathrm{HS}\left(\mathrm{CH}_{2}\right)_{8}-\mathrm{R}\left(\mathrm{R}:-\mathrm{CH}_{3},-\mathrm{CH}_{2} \mathrm{OH},-\mathrm{NH}_{2}\right)$ on the electrodesorption behaviour of well-formed SAMs (the selfassembled monolayers), their stability and blocking ability using voltammetry and chronoamperometry. The nature of the terminal functional group determines the surface properties of SAM and provides the basis for subsequent interactions (for example, with peptides, proteins, DNA) in order to create sensors and bioagents. For the studied thiols, the hydrophilicity of the end groups increases in the series $-\mathrm{CH}_{3}<<-\mathrm{NH}_{2} \leq-$ $\mathrm{CH}_{2} \mathrm{OH}$; they also differ in polarity and the possibility of protonation of the amino group. For thiols with $-\mathrm{CH}_{3}$ and $-\mathrm{CH}_{2} \mathrm{OH}$ groups, an increase in the hydrophilicity of the terminal group leads to the formation of less stable and less ordered films. The replacement of carbon by nitrogen with approximately the same hydrophilicity of the groups $\left(-\mathrm{CH}_{2} \mathrm{OH}\right.$ and $\left.-\mathrm{NH}_{2}\right)$ leads to the formation of a more stable film consisting of molecules in the same energy state, but with poorer insulating properties.
\end{abstract}

\section{Introduction}

The surface modification of metals via the self-assembled monolayers (SAMs) of thiols is an effective and widely used method. Highly ordered insulating films, formed during the adsorption of alkanethiols (AT) on the surface of various metals, are not only an interesting model system that allows one to change the properties of the interface and the rate of electron transfer in a predetermined manner by choosing thiols with different hydrocarbon chain length and various tail groups, but also the basis for the creation of nanodevices, including detectors, electro- and biosensors, means of controlled drug delivery, pre-stitched to the free terminal functional groups of SAMs [1]. It is known that in the case of $\mathrm{Au}$, which is characterized by the absence of stable surface oxides, the method of voltammetry (VA) allows one to obtain direct information about the adsorption region and the potential

- Corresponding author:ovchin@,solid.nsc.ru 
of the peak of the reductive desorption of AT, since on the voltammograms of the Au / AT electrode, the peaks of cathodic desorption of thiols are recorded up to the potentials of hydrogen evolution. In this case, the shape, magnitude of the desorption peak current and its potential are sensitive to the structure and properties of the SAMs [2].

In our work we studied the effect of the terminal group nature of AT with the same chain length $\mathrm{HS}\left(\mathrm{CH}_{2}\right)_{8}-\mathrm{R}\left(\mathrm{R}:-\mathrm{CH}_{3},-\mathrm{CH}_{2} \mathrm{OH},-\mathrm{NH}_{2}\right)$ on the desorption behaviour of wellformed SAMs, their stability and blocking ability using voltammetry and potentiostatic chronoamperometry. The nature of the terminal functional group (due to differences in polarity, hydrophobicity, steric effect, electrostatic and selective interactions, acid-base properties) determines the surface properties of SAMs and provides the basis for subsequent interactions (for example, with peptides, proteins, DNA) in order to create sensors and bioagents. For the studied thiols, the hydrophilicity of the end groups increases in the series $-\mathrm{CH}_{3}<<-\mathrm{NH}_{2} \leq-\mathrm{CH}_{2} \mathrm{OH}$; they also differ in polarity and the possibility to protonation of the amino group.

\section{Experimental procedure}

\subsection{Materials}

1-octanethiol $\left(\mathrm{CH}_{3}\left(\mathrm{CH}_{2}\right)_{7} \mathrm{SH}\right)$, 8-mercapto-1-nonanol $\left(\mathrm{CH}_{2} \mathrm{OH}\left(\mathrm{CH}_{2}\right)_{8} \mathrm{SH}\right)$ and 8-amino 1octanethiol $\left(\mathrm{NH}_{2}\left(\mathrm{CH}_{2}\right)_{8} \mathrm{SH}\right)$ (Aldrich), ethyl alcohol $\mathrm{C}_{2} \mathrm{H}_{5} \mathrm{OH}(96$ wt.\%) was used without any additional purification. The solutions were prepared from reagents of chemically pure grade $\mathrm{NaClO}_{4}$ and ultrapure water produced by Millipore purification systems (18 M $\Omega$ ). All measurements were carried out in naturally aerated solutions at room temperature. Since AT is practically insoluble in water, but well soluble in ethanol, the following procedure was used to obtain homogeneous aqueous solutions: a certain amount of an alcohol thiol solution was introduced into the base solution of $0.1 \mathrm{M} \mathrm{NaClO}$ while stirring, thus obtaining a colloidal solution with the required concentration of AT.

The working electrode was the end of Au wire (purity: $99.99 \%, 0.5 \mathrm{~mm}$ in diameter) sealed in teflon shell. The visible surface of the electrode was close to $2 \cdot 10^{-3} \mathrm{~cm}^{2}$ and was reproduced from one scrape to another with the accuracy not worse than $\pm 3 \%$ [3].

\subsection{Electrochemical measurements}

The studies were carried out using a software-controlled potentiostat (IPC-Compact, Institute of Physical Chemistry and Electrochemistry of the RAS, Moscow, Russia) and an electrochemical sensor, which includes a three-electrode cell and a device for mechanical renewal of the working electrode surface. The potential was measured relative to a saturated calomel reference electrode (SCE). The auxiliary electrode was a platinum wire with an area much larger than that of the working electrode. All values of the potentials in the article are given relative to the potential of the SCE. A flat end of Au wire ( $99.99 \%$ pure) with a diameter of $0.5 \mathrm{~mm}$, enclosed in an epoxy resin shell, served as a working electrode. The working electrode's surface was renewed before each measurement by scraping a thin $(2-3 \mu \mathrm{m})$ surface layer of metal using a hexanite rotating cutter directly in the test solution at a controlled potential [3]. Voltammograms were measured at a scan rate $(v)$ of $50 \mathrm{mV} \mathrm{s}^{-1}$. 


\subsection{SAMs formation}

AT SAMs was formed upon the contact of a clean (freshly scraped) Au electrode surface with a thiol-containing aqueous solution of $0.1 \mathrm{M} \mathrm{NaClO}_{4}(\mathrm{pH}=6)$ during the following stages: (a) renewal of the electrode surface by scraping the metal surface layer at an opencircuit potential, (b) adsorption of AT on Au surface for a certain time $(t)$ at a fixed potential $(\boldsymbol{E})$ while recording the $I, t$-curves $(\boldsymbol{I}$-current), (c) characterization of the blocking properties of the modified Au surface using cyclic voltammetry in the same solution.All stages are carried out in one aqueous solution with a low concentration of thiols at room temperature. The conditions for the formation of SAMs were the same for all studied thiols: the formation time of the insulating thiol films was $t_{\mathrm{SAM}}=120 \mathrm{~s}$; aqueous solutions containing $10^{-4} \mathrm{M}$ thiol, $0.1 \mathrm{M} \mathrm{NaClO}_{4}, \mathrm{pH}=6$; adsorption potential $\mathrm{E}=-200 \mathrm{mV}$.

Since the close-packed monolayer of thiol blocks the metal surface and, accordingly, the ability to transfer an electron across the phase boundary, the insulating properties of the AT film can be judged by a decrease in the rate of various electrochemical reactions occurring over the range of the SAMs stability potentials. For these purposes we used the current value for the reduction of oxygen dissolved in solution.

\section{Results and discussion}

Figure 1 shows cathode voltammograms obtained on modified with the studied thiols $(\mathrm{Au} / \mathrm{SAMs})$ electrodes. As can be seen, for a thiol with a non-polar hydrophobic $-\mathrm{CH}_{3}$ group a desorption signal with 2 peaks is recorded at potentials more negative than $-1.0 \mathrm{~V}$ (curve 1), reflecting the presence of two energetically different structures on the metal surface. Thiol with a methyl terminal group is also characterized by low oxygen reduction currents in the potential range from 0 to $-800 \mathrm{mV}$, which indicates a good insulating ability of the film. For thiol with a hydrophilic hydroxyl group (curve 2), a desorption signal with 2 peaks is also recorded, but the peaks are shifted towards positive potentials, which indicates a decrease in film stability. In this case, the value of the second peak for the thiol with a hydroxyl group is significantly higher than that for the thiol with a methyl group at the end. Another feature of the behaviour of a film with a hydroxyl end group is an increase in the current in the region of the reduction potentials of oxygen molecules, which indicates a higher permeability of this film compared to SAMs of a thiol with a methyl group.

For a thiol with a terminal amino group, there is a curve with an even higher second desorption peak (curve 3 ) recorded at a more negative potential than for the other two thiols, which indicates an increase in the stability of a film consisting mainly of molecules in one energy state, in which the molecules thiols are more strongly bonded to the gold surface. However, such a film structure promotes the permeability of particles through the film, as evidenced by the increased values of the current in the region of the reduction potentials of oxygen molecules.

For a thiol with a terminal $-\mathrm{NH}_{2}$ group the SAMs surface charge is determined by the acid-base equilibrium of the amino groups. As can be seen from Fig. 2, a decrease in $\mathrm{pH}$ from 6.0 to 3.5 does not affect the shape and magnitude of the desorption signal and currents in the region of the reduction potentials of oxygen molecules and hydrogen ions (up to $-0.8 \mathrm{~V}$ ). However, further protonation of the amino group leads to a sharp increase in the permeability of the film to $\mathrm{H}^{+}$ions. It can be seen that the reduction peak of hydrogen ions $(\sim-0.8 \mathrm{~V})$ on the background curve of pure Au (curve6) correlates with the peak at the $\mathrm{Au} / \mathrm{SR}-\mathrm{NH}_{2}$ electrode (curve 5). 


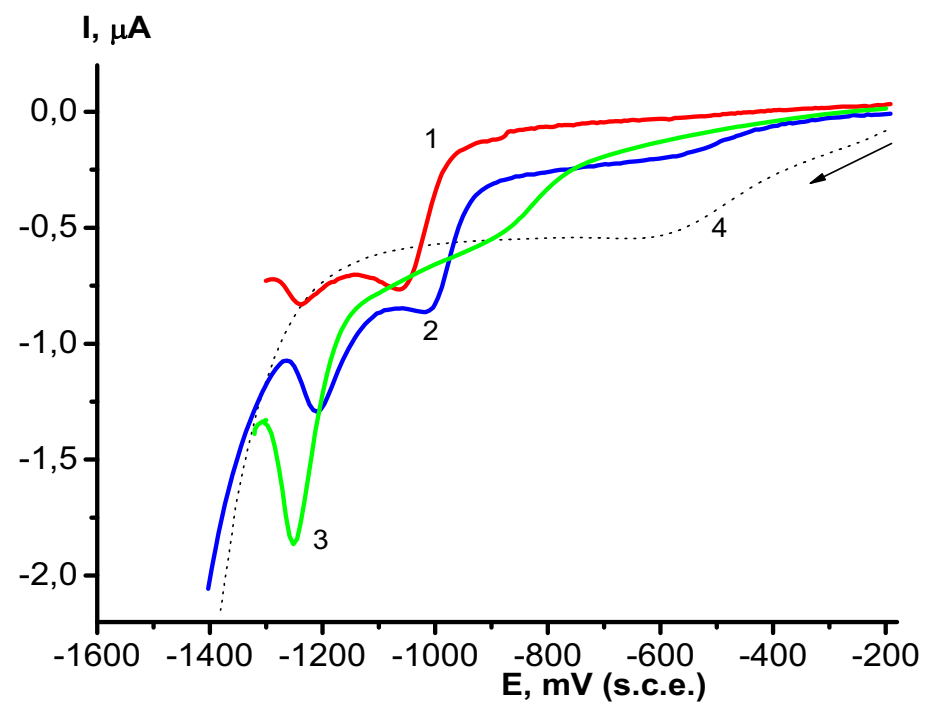

Fig. 1. Cathodic voltammograms of the $\mathrm{Au} / \mathrm{SAM}$ electrode obtained in the presence of $0.1 \mathrm{mM}$ thiols with different terminal groups: 1- $-\mathrm{CH}_{3}, 2--\mathrm{CH}_{2} \mathrm{OH}, 3--\mathrm{NH}_{2} ; 4$ - background curve on the $\mathrm{Au}$ electrode.

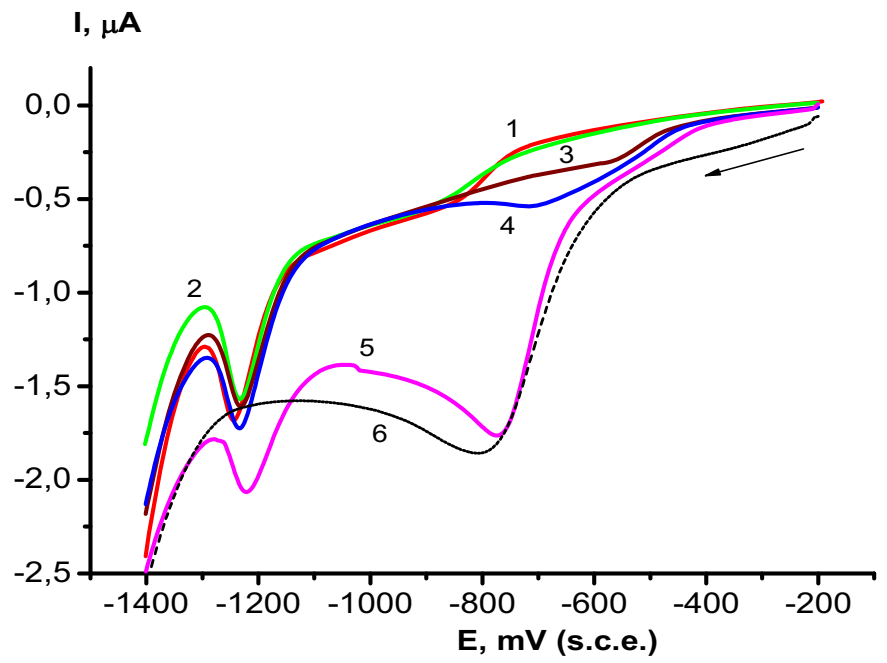

Fig. 2.Cathodic voltammograms of the $\mathrm{Au} / \mathrm{SR}-\mathrm{NH}_{2}$ electrode obtained in a solution of $0.1 \mathrm{mM}$ thiol and $0.1 \mathrm{M} \mathrm{NaClO} 4$ with different $\mathrm{pH}$ values $\left(+\mathrm{HClO}_{4}\right): 1-6.0,2-3.6,3-3.4,4-3.1,5-2.85$; 6background curve on $\mathrm{Au}$ for $\mathrm{pH}=2.85$. 
This behaviour of 8-amino-1-octanethiol films can be explained by the appearance of a second bond of the thiol molecule with the gold surface through nitrogen, which keeps the thiol molecules in the "lying" position: ${ }_{\mathrm{Au}}-\mathrm{S}-\left(\mathrm{CH}_{2}\right)_{8}-\mathrm{N}$..Au. An increase in the degree of protonation of the amino group does not lead to the appearance of thiol molecules in the "vertical" position, and, accordingly, to the formation of more ordered SAMs.

In this study we used chronoamperometry to investigate the dynamics of AT SAMs formation on $\mathrm{Au}$ surface and its desorption. SAMs formation was monitored by the extent to which adsorbed AT change the rate of oxygen reduction. Figure 3 shows $I, t$-curves of

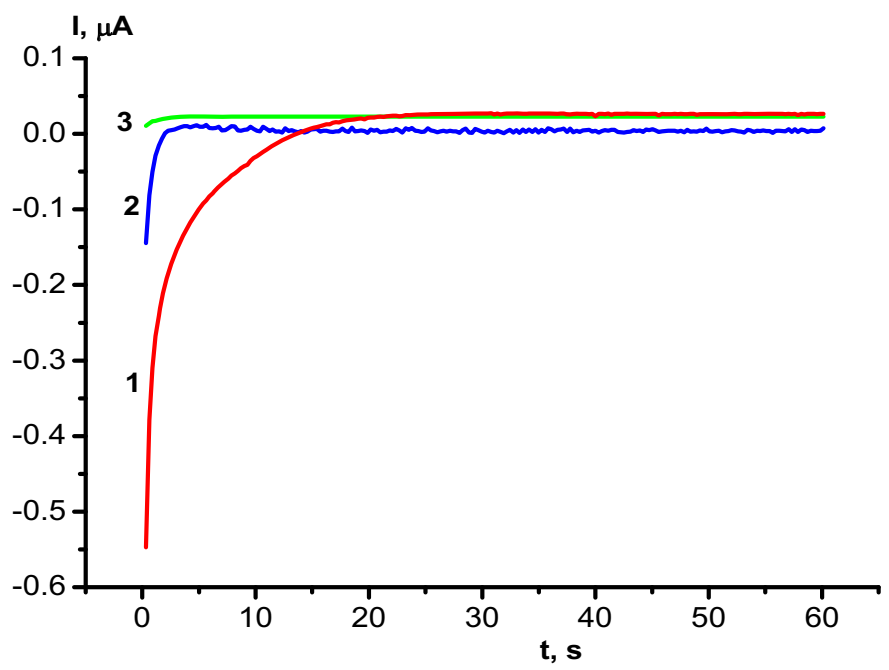

Fig. 3. Chronoamperograms recorded on $\mathrm{Au}$ electrode obtained at $\mathrm{E}=-200 \mathrm{mV}$ in the presence of $0.1 \mathrm{mM}$ thiols with different terminal groups: 1- $-\mathrm{CH}_{3}, 2--\mathrm{CH}_{2} \mathrm{OH}, 3--\mathrm{NH}_{2}$.

adsorption process for studied thiols. Three regions can be distinguished in curve 1 for $\left(\mathrm{CH}_{3}\left(\mathrm{CH}_{2}\right)_{7} \mathrm{SH}\right.$. A sharp decrease in current is observed within the first 5 seconds, and then current is decreasing gradually for a $20 \mathrm{~s}$. At the third region, a dense layer is detected, which blocks the electron transfer through the interphase boundary completely.On the I- $t$ curves characterizing the SAMs adsorption process, acceleration of the thiol adsorption process is observed in the series $-\mathrm{CH}_{3},-\mathrm{CH}_{2} \mathrm{OH},-\mathrm{NH}_{2}$ (Fig. 3).

We have recorded current - time transients for the desorption process of studied thiols, formed $120 \mathrm{~s}$ at $\mathrm{E}=-200 \mathrm{mV}$ (Fig. 4).In all cases $I-t$ curves exhibit a maximum in current, but for 8-mercapto-1-nonanol a curve with two peaks is observed which should be related to its slow kinetics for desorption. 


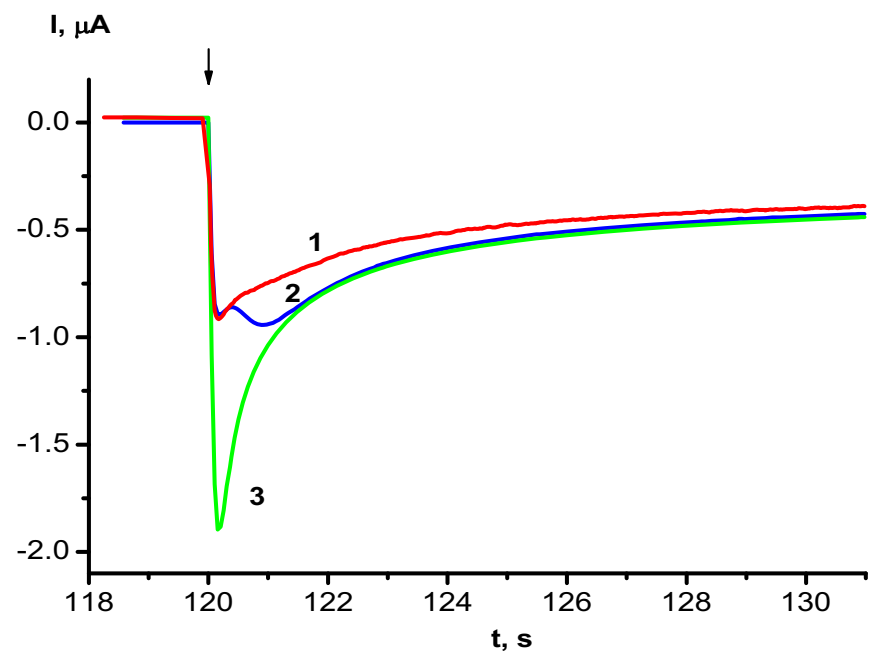

Fig. 4. Chronoamperograms for the desorption process recorded on $\mathrm{Au} / \mathrm{SAMs}$ electrode (formed 120 $\mathrm{s}$ at $\mathrm{E}=-200 \mathrm{mV}$ ) obtained at $\mathrm{E}=-1000 \mathrm{mV}$ in the presence of $0.1 \mathrm{mM}$ thiols with different terminal groups: 1- - $\mathrm{CH}_{3}, 2--\mathrm{CH}_{2} \mathrm{OH}, 3--\mathrm{NH}_{2}$. The arrow indicates the start of desorption.

\section{Conclusions}

Thus, for thiols with $-\mathrm{CH}_{3}$ and $-\mathrm{CH}_{2} \mathrm{OH}$ terminal groups, an increase in the hydrophilicity of the terminal group leads to the formation of less stable and less ordered films, which may be associated with the formation of hydrogen bonds in the polar $-\mathrm{CH}_{2} \mathrm{OH}$ group with solvent molecules. The replacement of carbon by nitrogen with approximately the same hydrophilicity of the groups $\left(-\mathrm{CH}_{2} \mathrm{OH}\right.$ and $\left.-\mathrm{NH}_{2}\right)$ leads to the formation of a more stable film consisting of molecules predominantly in one energy state, but with poorer insulating properties.

This research was carried out within the state assignment to ISSCM SB RAS (project 0301-20190003).

\section{References}

1. M.Galbiati, C.Barraud, S.Tatay, Adv. Mater. 24, 6429 (2012)

2. S.N. Ovchinnikova, Russ. J. Electrochem. 52, 260 (2016)

3. A.G.Zelinskii, R.Y. Bek, Russ. J. Electrochem. 21, 66 (1985) 